\title{
Artigo
}

\section{ADOLESCER EM CONTEXTOS DE VULNERABILIDADE E EXCLUSÃO SOCIAL}

\author{
Marisa Batista Warpechowski \\ Luciane De Conti
} inúmeras situações de abandono, violência e trauma, o que nos leva a interrogar sobre as vicissitudes e as estratégias de subjetivação desses jovens em contextos onde o viver se faz tão árido. Sustentados no referencial psicanalítico, procuramos explorar, a partir de recortes clinicos, as particularidades e as dificuldades no trabalho psíquico em curso nessa passagem para um adolescente com uma bistória marcada pela vulnerabilidade, pelo desamparo e por violências. Descritores: passagem adolescente; vulnerabilidade; exclusão social; desamparo; escuta psicanalitica.

DOl: https://doi.org/10.11606/issn. 1981-1624.v23i2p322-343.

\section{Introdução}

Este trabalho apresenta alguns interrogantes sobre a passagem adolescente em contextos de vulnerabilidade e exclusão social. Como se produz a passagem adolescente para esses jovens que vivem em contextos de miséria, abandono e violência, em

Psicóloga e psicanalista. Mestre pela Universidade Federal do Rio Grande do Sul (UFRGS). Associada efetiva da Associação

Psicanalítica de Porto Alegre (APPOA). Integrante da equipe técnica do Centro de Referência Especializada de Assistência Social - Fundação de Assistência Social e Cidadania (FASC), Porto Alegre, RS, Brasil.

口 Psicóloga e psicanalista. Professora do Programa de PósGraduação "Psicanálise: Clínica e Cultura" e do Departamento de Psicanálise e Psicopatologia do Instituto de Psicologia da Universidade Federal do Rio Grande do Sul (UFRGS). Membro do Núcleo de Ensino, Pesquisa e Extensão em Infância e Adolescência (NEPEIA/CNPq), Porto Alegre, RS, Brasil. 
comunidades submetidas ao abandono do Estado e em poder das organizações criminosas? Quem é esse adolescente? Que adolescência é essa? Quais as possibilidades de inscrição no laço social para esses adolescentes que já têm uma história que porta as marcas da exclusão? Tais questões nortearam a dissertação de mestrado da primeira autora ${ }^{1}$. A pesquisa se constituiu a partir da experiência de trabalho da autora no campo das políticas públicas em um Centro de Referência Especializado de Assistência Social (CREAS), que integra o Sistema Único de Assistência Social (SUAS).

$\mathrm{Na}$ referida pesquisa, as questões elencadas anteriormente foram desenvolvidas a partir da escuta de adolescentes atendidos no serviço, utilizando o dispositivo de rodas de conversa. As rodas de conversa eram quinzenais e os adolescentes eram convidados a participar sem obrigatoriedade. Para fins de pesquisa, examinamos as rodas durante oito meses, perfazendo um total de doze encontros. Participaram das rodas em torno de 23 adolescentes, havendo casos de única e rica participação. A partir das rodas de conversa, fomos recortando os significantes que emergiram no discurso desses jovens, o que nos possibilitou a construção de casos clínicos em que as dimensões subjetiva e política se enlaçam.

O caso clínico nessa pesquisa se apresenta como o produto extraído das intervenções da psicóloga-pesquisadora e do que decanta de sua escuta. Trata-se de colocar em jogo os significantes do sujeito e suas produções, visando traçar o caso a partir do discurso, daquilo que se produz desse encontro como efeito da escuta, movido pela transferência em curso. "Só assim será possível recolher dos infindáveis detalhes de uma história a direção de um caso. Enfim, uma história deve se fazer caso para que se possa trabalhar em psicanálise" (Figueiredo, 2004, p. 80).

Para este artigo, examinaremos, através de fragmentos de um caso, a passagem adolescente e as particularidades e dificuldades nesse processo para um jovem com história marcada pela vulnerabilidade, pelo desamparo e por violências, bem como suas estratégias de subjetivação. 


\section{O campo da experiência}

No CREAS, onde ocorreu a pesquisa, realizamos o acolhimento e o acompanhamento de famílias com as mais diversas situações de violações de direitos, como negligência com as crianças e/ou adolescentes, maus tratos, violência sexual, trabalho infantil, abandono, ato infracional, acolhimento institucional de crianças e adolescentes, entre outros.

O trabalho de escuta clínica sustentado pela psicanálise, realizado no campo da assistência social, tem nos levado a apontar, junto a outros autores como Broide (2008) e Rosa (2002a), que os sujeitos submetidos a condições de vulnerabilidades e exclusão social enfrentam constantemente situações de desamparo. Nesses casos, revela-se uma precariedade tanto de recursos materiais como simbólicos para enfrentar situações em que os acontecimentos são muitas vezes da ordem do destrutivo, do traumático, e os recursos para elaboração dos traumas são diminuídos ou dificultados, levando a processos dessubjetivantes. Ou seja, o sujeito fica colado, identificado com o lugar de resto, de dejeto que o discurso social inscreve sobre ele, e sua dimensão de sujeito de desejo, que tem uma história singular e também coletiva, fica relegada ao apagamento, ao silenciamento. Tomando em conta o discurso capitalista e seu imperativo de gozo, vemos a forte tendência a abolição da dimensão do semelhante transformando-o em puro objeto e, nestes casos, objetos a serem descartados, aniquilados.

Falamos de sujeitos com histórias de vida marcadas por muitas perdas, tanto afetivas como materiais. Crianças e adolescentes que crescem sem conhecer sua história, que circulam por várias famílias ou equipamentos de abrigagem, que sofrem situações de miséria, abandono, violência de várias ordens (familiar, de Estado), que habitam territórios e zonas irregulares e de risco, em moradias precárias, que ficam desatendidos em suas necessidades básicas (saneamento, energia, saúde, educação, trabalho).

Os adolescentes muito cedo abandonam a escola e se lançam em estratégias de sobrevivência pelas ruas, por meio de expedientes de trabalho infantil, mendicância, exploração sexual e do trabalho a partir do envolvimento com o tráfico de drogas, o que tem levado muitos desses jovens à morte ou ao encarceramento. Temos visto a cada dia aumentar o número de jovens ${ }^{2}$ que são mortos nesses territórios conflagrados pela violência e pela ausência do Estado em garantir políticas públicas efetivas e de qualidade. Também sabemos que são os jovens pobres e negros os que mais morrem no Brasil. Soares (2004) refere que, em função do que chama de "genocídio", já existe um déficit de jovens do sexo masculino em camadas da estrutura demográfica brasileira, condição esta que se assemelha à de sociedades que estão em situação de guerra. Foi a partir do trabalho nesse 
contexto que nos dedicamos a interrogar o trabalho psíquico em curso na passagem adolescente.

\section{Adolescência: implicações subjetivas de um processo de passagem}

Com a psicanálise, reconhecemos que a adolescência é o tempo de construir uma nova posição subjetiva, um tempo de elaboração da irrupção do real que a puberdade desvela, o que exige um intenso trabalho psíquico. Esse processo demanda uma reorganização pulsional, implicando a elaboração de vários lutos (do corpo, dos pais, e do meio social), que varia de intensidade e momento disparador. Assim, podemos falar que há várias adolescências, cada sujeito realizando essa passagem de modo singular com as incidências de seu contexto histórico e social.

Freud, nos Três ensaios sobre a teoria da sexualidade (1905/1972), já apontava a importância do período pubertário, em que mudanças significativas irrompem de forma abrupta produzindo efeitos na subjetividade. Ele situa a puberdade como o tempo do primado da genitalidade, do encontro com um objeto sexual alheio e tempo de conclusão do desenvolvimento psicossexual: "Com a chegada da puberdade, operam-se mudanças destinadas a dar à vida sexual infantil sua forma final normal" (p. 213).

A puberdade é um tempo de combinações e recomposições dos elementos da vida sexual infantil, constituindo-se num período em que pode ocorrer a produção de mal-estar e sofrimentos. Também a puberdade representa um momento importante de efetivação das diferenças sexuais e de busca pelo objeto sexual alheio. A satisfação antes autoerótica, com as zonas erógenas atuando de forma independente umas das outras, agora busca os caminhos em direção a um objeto externo (Freud, 1905/1972).

Uma predeterminação infantil vem a ser colocada à prova na puberdade. Agora o sujeito terá de dar conta do encontro com o Outro sexo, sendo este um tempo de construir novos arranjos.

Lacan (1999), no seminário As formações do inconsciente, constrói uma releitura do Édipo e da castração discorrendo sobre a metáfora paterna, oferecendo contribuições para a compreensão do que está em jogo na adolescência. Aponta o complexo de Édipo como

função normativa, não simplesmente na estrutura moral do sujeito, nem em suas relações com a realidade, mas quanto à assunção de seu sexo. . . . A virilidade e a feminilidade são os dois termos que traduzem o que é essencialmente a função do Édipo. (p. 171) 
As vicissitudes da passagem pelo Complexo de Édipo e a identificação construída com o pai produzem os elementos, "os títulos de propriedade" (Lacan, 1999, p. 176), que o sujeito usará quando chegar o momento da puberdade.

Essa passagem pelo Édipo coloca o sujeito em um enfrentamento radical com a falta e oferece também uma promessa. Essa promessa de gozo adiada para o "quando você crescer" se mostra enganadora, uma vez que o acesso ao gozo é sempre parcial. $\mathrm{Na}$ adolescência, a decepção que a promessa de um gozo outro apresenta traz duas consequências: o tornar-se grande exige uma reconstituição da imagem do corpo em valor e estatuto e também onde o Outro está em pane de consistência imaginária (Rassial, 1997).

Para Rassial (1999), “a puberdade fisiológica perturba a imagem do corpo construída na infância” (p. 17), ocorrendo uma mudança no estatuto imaginário do corpo. Ao adolescente cabe uma reapropriação da imagem corporal sob o olhar do Outro agora situado no campo da diferença sexual. As perguntas sobre o ser, sobre o sexo, sobre o próprio desejo e o desejo do Outro, surgidas na infância e silenciadas na latência são agora redespertadas na adolescência.

Temos um belo exemplo dessas questões no texto de Wedekind (1891), O despertar da primavera, em que o excesso pulsional, o saber sexual da infância não dá mais conta e o sujeito 
se defronta com a tarefa de construir um novo saber. Nessa peça vemos os protagonistas Melchior e Moritz no encontro com as primeiras sensações genitais, e em suas conversas se desvelam os enigmas sobre o sexo e a angústia que esse enfrentamento produz. Wedekind também apresenta o doloroso desafio de construir uma separação deste grande Outro primordial encarnado nas figuras parentais. A irrupção do real do sexo neste momento da puberdade tem mesmo o efeito de um raio, que pode desnortear e levar o adolescente ao confronto com algo da ordem do traumático, como expressa as palavras de Moritz: "Na hora eu pensei que um raio tinha me acertado" (p. 8). Interessante metáfora para dizer deste forte impacto que o enfrentamento com o real do sexo produz, na relação com o corpo, com o desejo, com o Outro sexo e com o Outro parental, ou, como melhor diz Lacan (1974/2003), "a sexualidade faz furo no real" (p. 562), com o despertar dos sonhos, exigindo a construção de um saber para velar a falta.

Freud (1905/1972) já destacava o afastamento dos pais como uma das realizações psíquicas mais significativas e também uma das mais dolorosas nesse tempo da puberdade. Será no rompimento com o amor incestuoso parental que o adolescente se dirigirá à cena social, onde outros objetos se apresentarão para substituir o objeto de satisfação perdido. No texto Romances familiares (1909/1976), Freud diz que para o desenvolvimento normal do sujeito e para o progresso da civilização essa operação de separação e ruptura entre duas gerações (pais e filhos) é fundamental.

Freud (1914/1974) destaca no texto Algumas reflexões sobre a psicologia escolar que todas as relações que o sujeito vai constituir ao longo da vida são substitutivas desses primeiros objetos. "Todas as escolhas posteriores de amizade e amor seguem a base das lembranças deixadas por estes primeiros protótipos" (p. 287). Nesse mesmo texto, aponta que o púbere transfere agora os sentimentos para a figura dos mestres, ou seja, que esses lugares parentais irão se recolocar no social, no público, refazem-se nas diferentes estruturas sociais. 
Compõe a trajetória adolescente interrogar os lugares materno e paterno, colocando-se em xeque qualquer forma de composição parental, frequentemente na forma de oposição e rebeldia. O Outro da infância sofre agora uma pane, caindo do lugar idealizado. Conforme Rosa (2002a), na adolescência novas operações se processam para validar outro discurso além do discurso paterno: "operações que possibilitam o pertencimento e o reconhecimento do jovem como membro do grupo social e que dependem das formas, condições e estratégias oferecidas pelo grupo social" (p. 230).

$\mathrm{O}$ adolescente tem de construir um lugar social que não é mais aquele da família, mas um lugar subjetivo enquanto sujeito no mundo. Faz parte dessa construção tomar a palavra e falar em nome próprio. Rosa (2010) reforça a importância dessa inscrição do jovem no laço social ao dizer:

Deve-se levar em conta que os processos do adolescente não se referem apenas à confirmação de certa estrutura subjetiva fixada e a priori. $\mathrm{O}$ adolescente reinscreve-se no laço social, superando, conservando e revelando o histórico do sujeito e conferindo-lhe novas significações. As ações ou acidentes, realizações, frustrações, encontros, desencontros, ou seja, os discursos e acontecimentos no campo social promovem reorganizações estruturais importantes no adolescente. (pp. 6-7)

A inscrição no laço social é um ponto fundamental na passagem adolescente. Podemos entender o laço social como um modo de tratamento do mal-estar que resulta da entrada do sujeito na cultura. Para Lacan o sujeito é prisioneiro da linguagem na qual se aliena e se transforma em ser da civilização. O conceito de laço social foi trabalhado por Lacan (1992) em suas proposições sobre a linguagem e o discurso como operadores da relação social. Lacan formula sua teoria do laço social a partir dos quatro discursos (do mestre, do analista, do universitário e o da histérica), em que podemos apreender que laços sociais são os laços discursivos. Com os quatro tipos de articulações discursivas, Lacan aponta as possibilidades de enlaçamento social sustentados por

328 Estilos clin., São Paulo, v. 23, n. 2, maio/ago. 2018, 322-343. 
quatro tipos de posições subjetivas. "Quatro lugares habitados pelo sujeito em seu enlaçamento com o Outro do social”" (Catroli \& Rosa, 2013, p. 306). Laço social é entendido como o

discurso que organiza a configuração das relações sociais, é também o nome dos momentos em que podem circular, ou não as palavras que dizem a origem, o lugar, a filiação, o mito, sem deixar de manter um hiato e uma equivocidade salutares. (Douville, 2004, p. 187)

Dessa forma percebemos que o conjunto de significantes colocados pelo Outro social aos adolescentes das vilas e periferias "são já marcados por significados portadores de desqualificação e geradores de dificuldades de inscrição adolescente no laço social" (Catroli \& Rosa, 2013, p. 302). Como produzir fissura nesses significantes cristalizados de forma a construir novos devires a esses jovens e possibilidades de inscrição no laço social menos degradadas e mortíferas?

A passagem adolescente é marcada para muitos jovens que habitam as vilas e periferias de nossas cidades por inúmeras situações de abandono, violência e trauma, o que nos leva a interrogar sobre as vicissitudes e as estratégias de subjetivação desses jovens em contextos onde o viver se faz tão árido.

\section{Tentativas de inscrição de um lugar na cena social: adolescer em contextos de vulnerabilidade e exclusão social}

Recortamos a seguir a fala de uma mãe que chega para atendimento junto ao $\mathrm{CREAS}^{3}$ :

Eu já disse pra vocês, eu não aguento mais. Tu não viu? O Pedro, assassinado com dois tiros na cabeça? O Luis, andava com ele, o Luís não me ouve, ele quebrou até a grade de casa para sair, não adianta falar, ele não ouve. Fim de semana ficou dois dias fora de casa e ontem dormin todo dia. Semana passada a Brigada me disse que não é com eles, que é com o Conselho e com a Assistência Social. Eu estou falando, qualquer dia é o Luís que vai aparecer morto por aí. Vocês têm que levar ele para o abrigo, eu não aguento mais.

Esse apelo se produz um dia após o assassinato de um adolescente em plena praça próxima ao $\mathrm{CRAS}^{4}$, ao posto de saúde, à escola, aos olhos de todos. Mais uma vez, a violência se presentifica em ato radical, mais uma vez a face da morte atinge um jovem, aumentando ainda mais as estatísticas de mortes violentas de jovens pobres no Brasil. Esse fato mobiliza todos (técnicos dos serviços no território, moradores, familiares) e aparece no discurso desesperado dessa mãe, por ela estar há muito tempo em dificuldades com seus filhos. 
A história dessa família é marcada por acontecimentos trágicos, a começar pelo suicídio do pai dos cinco filhos mais velhos, seguido pelo abandono do segundo companheiro, pai de três filhos, incluindo Luís ${ }^{5}$, que após várias situações de violência abandona a família.

Há pouco mais de dois anos a família foi abalada com a tentativa de assassinato sofrida por um filho aos 18 anos, ficando este paraplégico e com dependência total dos cuidados da mãe. Essa tentativa de assassinato ocorreu em decorrência do envolvimento do jovem com o tráfico de drogas. Por último, houve a prisão de outro filho após a casa ser invadida pela polícia de forma violenta.

Em meio a esse contexto marcado por violência e situações traumáticas, a mãe dá mostras de seu sofrimento, falando em todos os lugares (CREAS, Conselho Tutelar, escola) que lidar com os filhos e suas problemáticas está muito difícil e que às vezes tem até vontade de morrer, de desaparecer. Fala, assim, de um excesso, excesso de situações de difícil elaboração, o que apresenta sua marca de trauma. Destacamos o traumático como aquilo que está fora do sentido e da significação; não como a qualidade de um acontecimento, mas a desestruturante incidência subjetiva daquilo que irrompe sem uma trama de saber (Rosa, 2002a).

Essas são histórias e cenas comuns em nossas periferias, famílias fragilizadas por situações violentas, mães atônitas vendo seus filhos tomando o caminho do crime, vendo os filhos sendo assassinados e assassinando. Vidas que se sustentam tendo de articular uma multiplicidade de formas de sobrevivência, formas que conjugam um trânsito pelo legal e o ilegal, o lícito e o ilícito, o formal e o informal (Telles \& Hirata, 2007), marcando assim as dobraduras da vida nesses contextos.

As comunidades estão submetidas a muitas violências: ao abandono social, pela ausência do Estado, à força paralela e perversa do tráfico de drogas, à ação policial que muitas vezes se impõe de forma arbitrária e desumana sobre os jovens e suas famílias. Essas violências sofridas se repetem na relação familiar, na qual é comum que a resolução dos conflitos se faça também por meios violentos. "São espaços que podemos chamar de potencialmente traumatizantes" (Endo, 2005, p. 225), onde há uma desregulação e ausência de qualquer proteção ao cidadão que circula e habita esses territórios.

É nesse contexto de violência, abandono e trauma que Luís vive sua passagem adolescente. Luís, 14 anos, desde os 11 anos já não consegue permanecer na escola, seguindo-se uma série de tentativas da mãe e dos serviços que atendem a família de incluí-lo em espaços educativos e protetivos, mas algo aí não se produz, uma vez que ele não constituiu laço com nenhum serviço (escola, serviços de extraclasse, escola de futebol, 
espaço de tratamento), e os limites e ordens da mãe são contestados e desobedecidos, assim como também as regras da escola e de outros espaços educativos. Vemos, assim, Luís num tempo subjetivo de oposição e rebeldia, um tempo de contestação do discurso parental e em busca de novos referenciais no campo social.

Sobre Luís muitos falam, a começar pela mãe, que diz do quanto lhe é insuportável acompanhar o adolescer desse filho. Seu discurso é marcado por significantes que apontam para um desfecho também trágico; teme que o filho se envolva com drogas e com o tráfico.

Nas escolas por onde passou há um discurso de impotência (logo, nenhum investimento) e a suspeita de que Luís esteja sendo "aviãozinho" para o tráfico. No serviço de extraclasse $^{6}$, Luís aceitou o convite para participar e começou a esboçar a construção de um vínculo, mas os frequentes episódios de agressividade com os colegas e até com educadores levaram ao seu afastamento do espaço, ficando o retorno condicionado à comprovação de tratamento em saúde mental.

Lembramos, com Lacan (1986) e Guerra, Soares, Pinheiro \& Lima (2012), que o ato agressivo seria uma exacerbação da agressividade estrutural que compõe a relação original do sujeito falante com a alteridade, apontando, assim, a agressividade como força necessária para que o sujeito, inscrito seu desejo como desejo do Outro, possa desse Outro se separar.

$\mathrm{Na}$ origem, antes da linguagem, o desejo só existe no plano da relação imaginária do estado especular, projetado, alienado no outro. A tensão que ele provoca é então desprovida de saída, quer dizer, não tem outra saída... senão a destruição do outro. (Lacan, 1986, pp. 197-198)

Se a entrada na ordem simbólica é bem-sucedida, essa saída se dá pela via da palavra. Mas se a palavra não é suficiente para tratar esse excesso, o ato agressivo pode surgir no lugar da palavra que não advém. Podemos interrogar se Luís, através desses atos agressivos, não estaria construindo uma tentativa de separação, uma tentativa de demarcar seu lugar e sustentar seu desejo.

$\mathrm{O}$ que vimos foi que o serviço de extraclasse, assim como a mãe de Luís, também não suportou acolher seus atos e tratou de decidir pela sua exclusão do espaço de atendimento, judicializando as relações, ou seja, encaminhando o adolescente à delegacia para registro de ocorrência policial, fechando com isso a possibilidade de escuta, mediação e responsabilização por parte do adolescente.

As tentativas de atendimento em saúde mental também fracassam. Luís diz "não sou louco", uma vez que, em seu imaginário, psiquiatra e psicólogo é para louco. Então, não aceita ir para a consulta no serviço 
de saúde, ficando inviabilizado o seu retorno ao serviço de extraclasse.

Luís pode não ser louco, mas seus atos apontam para um mal-estar. Assim, apostando no vínculo que temos com ele por meio dos atendimentos a sua família no CREAS, vamos conversando e nos dispondo a escutá-lo nos lugares onde os encontros se produzem: nas visitas domiciliares, na rua, na praça, no CREAS, até ele poder, a partir da oferta de um lugar de escuta, construir uma demanda.

O trabalho com a família de Luís tem início a partir do encaminhamento de um Centro de Referência InfantoJuvenil que realiza avaliações e perícias envolvendo crianças e adolescentes vítimas de violências. A família chega ao CREAS para atendimento devido a denúncias de maus tratos da mãe em relação aos filhos, e durante os atendimentos vai se desdobrando a história familiar e as problemáticas de cada membro da família. Foi neste contexto de atendimento que chegamos a Luís e com o qual começamos a trabalhar, inicialmente a partir das demandas e queixas de sua mãe, mas também simultaneamente com ele na tentativa de compor com o próprio garoto seu retorno para a escola, a busca por uma escola de futebol e nas mediações com as dificuldades surgidas nestes espaços. O trabalho clínico possível com esse adolescente ocorreu na diversidade das intervenções, em que, em cada encontro, que ocorria em diferentes lugares, sempre o convidávamos à conversa. São estratégias que podem provocar o rompimento da alienação e redesenhar uma ficção de si mesmo e do outro para apoio na produção de um lugar discursivo (Rosa, 2012).

O trabalho nesses contextos põe à prova o desejo do analista e seus ideais de análise baseados nas estratégias convencionais, levando-nos a trabalhar com a escuta clínica em diferentes espaços onde os encontros se produzem. Há, assim, uma ampliação e uma recriação do setting, inscrevendo-se no campo de práticas que podemos chamar de clínico-políticas, lançando desafios e exigindo estratégias no âmbito do sujeito e das práticas sociais (Catroli \& Rosa, 2013; Rosa, 2012).

332 Estilos clin., São Paulo, v. 23, n. 2, maio/ago. 2018, 322-343. 
Guerra e Martins (2013), valendo-se de um recurso topológico - a faixa de Moebius -, partem da premissa de que a "dimensão política e a dimensão inconsciente são os dois lados correlativos de uma mesma lógica de agenciamento do funcionamento do sujeito no laço social" (p. 93), apontando que mudanças em um plano levariam também a mudanças no outro. Supõem que "intervir no campo político afeta o sujeito e intervir no plano inconsciente afeta o morador da pólis" (p. 93).

A aposta de oferecimento de escuta produz seus efeitos, e Luís, em certo encontro, revela um sofrimento nos endereçando um pedido de ajuda, pois não quer voltar a usar drogas. Conta-nos do medo que vem sentindo em voltar a usar drogas, relatando o mal-estar vivido na última vez em que usou. Passa a narrar uma sensação muito aterrorizante que sentiu, na qual parecia que iria "engolir a língua", sentindo-se sufocado e com dificuldade de respirar. No desdobramento deste encontro que ocorreu em sua casa em uma visita domiciliar, Luís aceita o convite em ir até ao CREAS para participar das rodas de conversa. Aqui já não é a mãe quem demanda ajuda para o filho, mas Luís quem nos fala de seu sofrimento, daquilo que lhe faz questão.

Esses significantes, "engolir a língua" e "sufoco", dizem muito da posição subjetiva de Luís nesse contexto, onde a palavra é silenciada pela violência e o sufoco explode em atos agressivos. Sustentado pela transferência, Luís frequentou por certo período um espaço de rodas de conversa oferecido a adolescentes, que desenvolvemos no CREAS. Nesse espaço, ele "solta a língua", começa a falar e compartilhar sua história e suas dificuldades e também a dizer de seus desejos e interesses. Para isso, cria uma ficção mostrando-se forte e valente.

Nos encontros, Luís fala das andanças pela comunidade onde mora, uma comunidade como tantas outras, marcada por situações de violência e pelo tráfico de drogas, onde a morte pode estar à espreita em cada beco.

A violência nas periferias traz como consequência a manutenção do sujeito em alerta máximo, acontecimentos destrutivos podem acontecer a qualquer momento. O que se instala então é ação reativa que alimenta o circuito fechado da violência, o sujeito estar tomado pelo medo faz com que tenha de mostrar-se valente e violento. (Broide, 2008, p. 116) É mostrando-se valente que Luís nos fala do desejo de vingar o irmão que caiu vítima da guerra do tráfico. É estando cada vez mais na rua que enfrenta a perda do amigo assassinado. E para enfrentar o medo nos conta seus conhecimentos para escapar do tiroteio ("tem que correr em ziguezague") e fala da rebeldia ao desrespeitar o toque de recolher em sua comunidade, passando a compartilhar vários episódios de violência sofridos por seus amigos. Nesse espaço de circulação da palavra, Luís 
vai constituindo uma ficção que lhe permite a construção de um saber para operar neste contexto. Sua corrida em ziguezague mostra a ginga e a flexibilidade que é preciso ter para ir driblando os obstáculos que a vida impõe aos jovens nas periferias.

É como resistência a esses processos que geram o silenciamento, a supressão da palavra, "o sufoco", "O engolir a língua” e que impelem à ação que oferecemos escuta a Luís. Em seu dizer vão surgindo significantes que podem apontar para outras direções, novas alternativas de inscrição.

Luís relatou que estava vendendo balas, mostrando-se um esperto comerciante, avaliando que rendem mais que a venda da maconha, uma vez que as balas são produto próprio, não tendo que dividir o que ganha com o dono do produto, como no caso da maconha. Relata a história do irmão mais velho, que desde os oito anos também vendia balas e hoje conseguiu trabalho, construiu família, casa e ganha mais de dois mil reais por mês, enfatiza Luís. Ele parece vislumbrar outro caminho, outro referencial identificatório, diferente do apontado pelo temor materno e também pelo Outro social que lhe aponta um destino de delinquência e violência expresso no significante "aviãozinho", emitido pela escola. Luís fala não do irmão que quase morreu vítima do tráfico, nem do irmão que foi para cadeia, mas de um terceiro irmão, que construiu uma saída pelo trabalho. Diz também que não quer vender bala para sempre; quer ser engenheiro, mas que para a escola não quer ir, só se puder frequentar à noite, anunciando assim que parece não encontrar mais seu lugar entre as crianças, construindo uma aposta na escola noturna, "lugar dos grandes", endereçando um pedido de que o ajudássemos a conseguir uma escola noturna. Em suas palavras, aponta o desejo de aceder a outro lugar, outra posição, de vendedor de balas a engenheiro, da escola diurna à escola noturna.

Luís relata também seu trabalho de cuidar de carros, que realiza em um espaço bastante reconhecido socialmente e que há pouco tempo passou a existir nesse território, o estádio de futebol de um time famoso. Isso abriu uma frente de trabalho informal para muitas famílias do local, mas não abre acesso para adolescentes como Luís entrarem no estádio para visitar e conhecer, nem assistir a um jogo. A eles o lugar destinado é a rua e o trabalho infantil, somente o lado de fora do estádio, revelando assim os lugares destinados às diferentes classes sociais.

É frequente encontrá-lo trabalhando junto a esse estádio, em situação malvista pelas políticas públicas, que dizem que essa condição é trabalho infantil e, portanto, proibida, ilegal, mas sem interrogarem o valor subjetivo desse trabalho para o sujeito nem construírem com ele e sua família outras alternativas de renda. 
Nessas atividades de trabalho, em geral Luís circula em meio a adultos, demonstrando agilidade e esperteza, parecendo ter bem mais que seus 14 anos. Além do trabalho, a religião também parece ter sido uma tentativa de busca de inscrição. Luís começou a frequentar uma igreja evangélica, a participar de cultos e de vigílias. Passava algumas noites em vigília, sentindo-se convocado a sair fazendo pregações. Nesse período, vestia-se com terno e gravata, presente que recebeu do pastor, figura que por certo tempo serviu-lhe de referência. Sua circulação pela vila vestindo terno causava estranheza. O figurino contrastava com a pobreza dos becos, mas imaginariamente o colocava em outra posição, em outro lugar social.

Quanto a seu pai, após muito tempo sem vê-lo e sem saber onde encontrá-lo, avista-o por acaso na rua e, a partir desse encontro casual, passa a visitá-lo nas obras de construção civil onde eventualmente trabalhava. Certo tempo depois, conta que aprendeu a pintar com o pai e fala do desejo de ser engenheiro, esboçando assim uma faísca de identificação.

Essas visitas ao pai logo se interrompem, justamente porque depara com o abandono de um pai que não lhe conta onde está morando, não lhe fornece nem o telefone, não o visita, abandonando-o mais uma vez ao trocar de trabalho. Em narrativa compartilhada na roda de conversa, fala de sua decepção com o pai ao dizer não ter pai, que "a mãe é mãe e pai", "é ela que cuida de nós", mas se mostra valente dizendo que se o pai não se importa com ele, também não quer saber dele. Luís parece aqui ter se enfrentado com a queda do pai e a partir de agora passa a elaborar esse abandono, reconhecendo na mãe o lugar de proteção e cuidado.

Luís se lança em busca de outros referentes no campo social, na religião, na relação com o pastor, no lugar imaginário do pregador, entre os cuidadores de carros, entre vendedores e também entre os traficantes do território.

As alternativas de inscrição no laço social construídas por esse adolescente devem produzir interrogantes às políticas públicas. Por que um adolescente não consegue encontrar mais sentido em estar no espaço escolar? Será que o conhecimento que a escola transmite permite a adolescentes como Luís operarem em seu mundo? Ou mais uma vez inscreve a violência simbólica sobre o sujeito? Chama a nossa atenção que a cada ano Luís faça uma nova tentativa de retorno à escola, mas seu desejo novamente sucumbe apesar do caderno novo comprado com esforço pela mãe. Agora tem como próxima aposta a escola noturna, quando atingir a idade mínima necessária para poder acessar.

Os programas que visam à qualificação profissional e à inserção no mercado de trabalho, como Jovem Aprendiz ${ }^{7}$ e Aprendiz Legal ${ }^{8}$, apresentam critérios dos quais Luís e a grande parte dos adolescentes das vilas e periferias ficam excluídos. Em geral, esses programas exigem justamente o que eles não têm: a 
escolaridade. Como incentivar um jovem a retomar três ou quatro anos de escola para só assim poder ser incluído no Jovem Aprendiz? Qual empresa abre espaço para contratar o adolescente da favela com baixa escolaridade? Qual a empresa disposta a abrir uma possibilidade para o adolescente autor de ato infracional? Lamentavelmente, a esta altura o tráfico de drogas já o acolheu e lhe apontou um plano de carreira mais rápido e vantajoso.

O que fazer neste tempo em que o que está previsto para sua faixa etária parece não fazer sentido a ele? O tempo de espera e elaboração próprio da operação adolescente parece abreviado nesses contextos. É importante considerar que as crianças e os adolescentes dessas comunidades desde muito cedo são forçados a "se virarem", construindo forçadamente certa autonomia e independência, fruto também das situações de desamparo e desproteção que vivem desde muito cedo. Assim, logo assumem responsabilidades, e o trabalho adquire mais importância do que a formação escolar, uma vez que a luta pela sobrevivência se impõe precocemente a esses jovens, e muitas vezes a família não consegue ou não tem condições de suprir os desejos e as necessidades do adolescente, cabendo a ele mesmo a responsabilidade de se sustentar e também de ajudar a família.

$\mathrm{Na}$ marginalidade, Luís vai mostrando seu padecimento. Os desejos encontram poucas vias de expressão e de reconhecimento. Do lado da família, só existe o temor de que, se está na rua, está na droga, está no tráfico, embora a mãe aceite o dinheiro que traz com o trabalho que realiza. As possibilidades de inclusão em programas de qualificação, trabalho e educação lhe restringem o acesso, uma vez que ainda não tem a idade mínima nem a escolaridade exigida, e o que é oferecido parece não lhe fazer sentido.

Os desejos enunciados por esse adolescente e reconhecidos num espaço de escuta interrogam o campo das políticas públicas. Estamos, assim, diante de um sujeito que deseja outra coisa além do que lhe é permitido. Como construir um lugar no laço social neste momento que não seja na marginalidade? Como acolher essas demandas?

336 Estilos clin., São Paulo, v. 23, n. 2, maio/ago. 2018, 322-343. 
Temos, então, um adolescente fazendo uma travessia, na corda bamba, tentando encontrar um espaço de reconhecimento. Nessa travessia, vai flertando com diferentes possibilidades de inscrição, ora trabalhador (cuidador de carro, vendedor), ora pequeno traficante (venda de maconha), ora pastor evangélico. Nesse espaço da dúvida, ainda podemos investir no que Guerra (2016) chama de "potência da indeterminação".

Luís, através de seu padecimento, assim como sua mãe, também demanda abrigo. Ao escutar a polissemia de sentidos, entendemos que abrigo é também refúgio, proteção, amparo, acolhida. Assim, a partir de seus atos e sintomas, diz da busca de reconhecimento e inscrição na cena social. No entanto, muitas vezes, como lembram Catroli e Rosa (2013), o lugar que é destinado ao jovem em um determinado contexto social pode produzir apenas abandono e deriva subjetiva. O imaginário social evidencia, segundo Castoriadis (1988), o lugar concreto que ocupam os indivíduos na sociedade. Tais lugares permitem hipotetizar de que forma as realidades ou fantasias dos grupos sociais produzem discursos e atribuem lugares específicos ao jovem no imaginário social e parental.

Conforme Rosa (2002b), a construção da subjetividade fica articulada aos laços sociais possíveis em dados grupos sociais, podendo promover mudanças estruturais ou vinculações a laços sociais perversos.
Muitas imagens sobre o jovem circulam no imaginário social, principalmente sobre o jovem que habita as vilas e as periferias das grandes cidades, e esse imaginário social o alia muitas vezes à violência, à delinquência e à agressividade. No caso de Luís, apesar do discurso desesperado da mãe que aponta ao filho um destino trágico, procuramos não nos deixar capturar por esse horror, e o "abrigo" que oferecemos a ele foi a possibilidade de acolhida de sua palavra e a aposta de que pudesse construir um lugar pela via do trabalho, compondo com ele formas de poder exercer suas atividades com menos riscos, construindo algumas alternativas de cuidado.

Podemos tomar os atos de Luís como certa denúncia frente ao desamparo, quer pela fragilidade na identificação paterna, quer por sua fragilidade em lidar com os imperativos e valores sociais priorizados na cultura. Do lado de sua família, temos a mãe que diz de uma impossibilidade de reconhecer um saber próprio acerca do que se passa com seu filho, delegando a outros (abrigo) a possibilidade de lidar e construir limites e proteção, denunciando assim sua frágil sustentação simbólica. Do lado das instituições, a impossibilidade de ser continente e oferecer amparo, surgindo às exigências o regramento e a exclusão.

Não será justamente a ausência de outra forma de reconhecimento e inscrição na cena social desses jovens, além da fragilização das referências 
familiares, o que tem levado muitos deles ao envolvimento com o tráfico e delinquência? O que esses adolescentes interrogam ao campo das políticas públicas em seus serviços e programas? Que outras alternativas o Estado tem apontado a estes jovens? Não é chegada a hora de o poder público considerar certas especificidades dos adolescentes que vivem em contextos de vulnerabilidade e exclusão para, a partir de uma escuta e de práticas interdisciplinares, construir políticas públicas mais inclusivas?

Rosa e Vicentin (2010) denunciam a crescente criminalização e patologização da juventude pobre como forma de encobrir determinados processos sociais que discriminam a pobreza e encobrem o desinvestimento da sociedade em relação a estes jovens. Acrescentam a necessidade de ampliar o olhar e a ação para a complexa e muitas vezes restrita trama na qual eles se inserem socialmente, apontando que somente uma articulação coletiva entre diversos atores sociais e instituições que acompanham esses adolescentes poderá criar alternativas a esse circuito.

\section{Tempo de concluir}

Não podemos pensar a passagem adolescente sem levar em conta toda essa trama social, sem a análise das relações sociais nas quais esses jovens estão imersos e que fazem marca na 
subjetividade. A escuta desses adolescentes nos permite apontar que essa trama social traz dificuldades e limites na inscrição desses jovens no laço social em um lugar de reconhecimento e pertencimento.

No caso apresentado podemos observar que Luís constrói uma ficção de valentia, de rebeldia, para se proteger do medo e do desamparo frente a tantas situações de violência sofridas desde muito cedo. Constrói uma estratégia de subjetivação que o leva a ter dificuldades em constituir vínculos para se proteger do abandono; pelo medo, torna-se violento, vai para a rua e se esforça em configurar um lugar de reconhecimento.

Acompanhamos as várias tentativas de Luís em construir um lugar na cena social que passam por experimentar posições que vão do lugar do criminoso, do traficante ao lugar do trabalhador. Vai experimentando diferentes possibilidades de acordo com aquilo que seu contexto social oferece. Traficante, vendedor, pastor, guardador de carros, aluno na escola noturna, engenheiro.

Construir com os adolescentes dispositivos em que a palavra de cada um possa ter lugar é uma forma de ressignificar subjetivamente o sujeito perante a cena social; é também compartilhar histórias e experiências e descobrir desejos e projetos. É uma forma de construir práticas de resistência à exclusão da dimensão subjetiva; é também uma forma de construir amparo durante este intenso trabalho psíquico que representa adolescer. Além da dimensão subjetiva, devemos articular a dimensão política convocando intervenções com as demais políticas públicas, como a cultura, o esporte, a educação, a geração de renda, visto ser este um ponto de muita importância para todos os adolescentes que escutamos.

Nossa função a partir da psicanálise é investir na construção de dispositivos clínicos que sirvam de resistência nestes tempos sombrios, possibilitando a circulação da palavra. Colocar palavras é nomear conflitos, expressar dificuldades e desejos, poder sentir a dor da perda, deparar com o desamparo, o medo. É também encontrar talentos, viver o encontro criativo com o outro, construir caminhos e alternativas (Broide, 2010).

Trata-se de oferecer abrigo à produção da palavra e, nesse sentido, acolher o sofrimento, dar amparo para que essa passagem adolescente possa se produzir e que Luís possa construir um novo lugar no campo social, uma posição que lhe permita localizar-se no mundo e estabelecer laços sociais, pois quando o sujeito é escutado, é possível descansar, apaziguar a angústia vivida, é possível sair do sufoco.

Apostamos que o acolhimento e a escuta ao sujeito, como aponta Torossian (2011), pode representar um momento de ruptura e abertura para a construção de outras versões discursivas. 


\begin{abstract}
This study discusses the adolescent passage, examining how this process is produced in young people who live in vulnerability and social exclusion contexts, assisted at a Specialized Reference Center for Social Assistance (CREAS). The adolescent transition is marked by many situations of abandonment, violence and trauma for many young people who live in the outskirts of our cities, which leads us to question the vicissitudes and strategies of subjectivation of these young people in contexts in which living is too arid. Supported by the psychoanalytic framework, we seek to explore, from clinical clippings, the particularities and difficulties of the psychical work. (underway in) of this passage for adolescents whose histories are marked by vulnerability, helplessness and violence.
\end{abstract}

Index terms: adolescent passage; vulnerability; social exclusion; helplessness; psychoanalytic listening

\title{
SER ADOLESCENTE EN CONTEXTOS DE VULNERABILIDAD Y EXCLUSIÓN
} SOCLAL

\section{Resumen}

Este trabajo discute la adolescencia, desde el análisis sobre cómo se produce ese proceso en jóvenes en contextos de vulnerabilidad y exclusión social, atendidos en un Centro de Referencia Especializado de Asistencia Social (CREAS). Para muchos jóvenes que viven en las periferias de nuestras ciudades, la adolescencia está marcada por innumerables situaciones de abandono, violencia y trauma, lo que nos lleva a interrogar sobre sus vicisitudes y estrategias de subjetivación en contextos donde vivir se hace tan árido. En base del referencial psicoanalítico se busca explorar, a partir de recortes clínicos, las particularidades y las dificultades en el trabajo psíquico en curso del ser adolescente con historia marcada por la vulnerabilidad, el desamparo y las violencias.

Palabras clave: ser adolescente; vulnerabilidad; exclusión social; desamparo; escucha psicoanalitica.

\section{REFERÊNCIAS}

Broide, J. (2008). Psicanálise nas situaçôes sociais críticas; violência, juventude e periferia em uma abordagem grupal. Curitiba, PR: Juruá Psicologia.

Broide, J. (2010). Adolescência e violência: criação de dispositivos clínicos no território conflagrado das periferias. Revista Psicologia Politica, 10(19), 95-106. Recuperado de http://pepsic.bvsalud. org/scielo.php?script=sci_arttext\&pid=S1519-549X2010000100009\&lng=pt\&tlng=pt ISSN1519-549X

Castoriadis, C. (1988). Los dominios del hombre. Barcelona: Gedisa.

Catroli, V. S. C., \& Rosa, M. D. (2013). O laço social na adolescência: a violência como ficção de uma vida desqualificada. Estilos da Clínica, 2(18), 297-317. Recuperado de http://www. revistas.usp.br/estic/article/viewFile/79850/83807

Douville, O. (2004). Uma melancolização do laço social? Ágora, 7(2), 179-201. Recuperado de http://www.scielo.br/pdf/agora/v7n2/v7n2a01

340 Estilos clin., São Paulo, v. 23, n. 2, maio/ago. 2018, 322-343. 
Endo, P. C. (2005). A violência no coraçâo da cidade: um estudo psicanalítico. São Paulo, SP: Escuta/Fapesp.

Figueiredo, A. C. (2004). A construção do caso clínico: uma contribuição da psicanálise à psicopatologia e à saúde mental. Revista Latinoamericana de Psicopatologia Fundamental, 7(1), 75-86.

Freud, S. (1972). Três ensaios sobre a teoria da sexualidade: parte III: as transformações da puberdade. In S. Freud, Edição standard brasileira das obras psicológicas completas de Sigmund Freud (Vol. VI, pp. 213-236). Rio de Janeiro, RJ: Imago. (Trabalho original publicado em 1905).

Freud, S. (1974). Algumas reflexôes sobre a psicologia escolar. In S. Freud, Edição standard brasileira das obras psicológicas completas de Sigmund Freud (Vol. XIII, pp. 285-288). Rio de Janeiro, RJ: Imago. (Trabalho original publicado em 1914).

Freud, S. (1976). Romances familiares. In S. Freud, Ediçâo standard brasileira das obras psicológicas completas de Sigmund Freud (Vol. IX, pp. 241-247). Rio de Janeiro, RJ: Imago. (Trabalho original publicado em 1909).

Guerra, A. M. C. (2016). Trauma e mal-estar: sempre atual, sempre a enfrentar. Aula inaugural ministrada no Programa de Pós-Graduação em Psicanálise: Clínica e Cultura, Instituto de Psicologia. UFRGS, Porto Alegre/RS, 7 mar. 2016.

Guerra, A. M. C., \& Martins, A. S. (2013). Psicanálise e política: contribuições metodológicas. Revista Borromeo, (4), 90-111. Recuperado de https:/www.veredaspsi.com.br/wp-content/ uploads/2018/04/psicanalise-e-politica-contribuicoes-metodologicas.pdf

Guerra, A. M. C., Soares, C. A. N., Pinheiro, M. C. M., \& Lima, N. L. (2012). Violência urbana, criminalidade e tráfico de drogas: uma discussão psicanalítica acerca da adolescência. Psicologia em Revista, 18(2), 247-263.

Lacan, J. (1986). O seminário, livro 1: os escritos técnicos de Freud, 1953-1954. Rio de Janeiro, RJ: Jorge Zahar.

Lacan, J. (1992). O Seminário, livro 17: o avesso da psicanálise, 1969-1970. Rio de Janeiro: Jorge Zahar.

Lacan, J. (1999). O seminário, livro 5: as formações do inconsciente, 1957-1958. Rio de Janeiro, RJ: Jorge Zahar.

Lacan, J. (2003). Prefácio a O despertar da primavera. In J. Lacan, Outros escritos (pp. 557-559). Rio de Janeiro, RJ: Jorge Zahar. (Trabalho original publicado em 1974).

Rassial, J. J. (1997). A passagem adolescente: da família ao laço social. Porto Alegre, RS: Artes \& Ofícios.

Rassial, J. J. (1999). O adolescente e o psicanalista. Rio de Janeiro: Jorge Zahar.

Rosa, M. D. (2002a). Adolescência: da cena familiar à cena social. Psicologia USP, 2(13), 227-241. Recuperado de http://dx.doi.org/10.1590/S0103-65642002000200013

Rosa, M. D. (2002b). Uma escuta psicanalítica das vidas secas. Revista Textura, (2), 1-13.

Rosa, M. D. (2010). O jovem e o adolescente na cena social: a relação identificação, ato e inserção no grupo social. In Políticas Públicas em Debate: Ciclo de Seminários: Seminário Juventude Juventudes: presente e devir, 2010, São Paulo, SP. São Paulo, SP: Fundap. Recuperado de https://craspsicologia.files.wordpress.com/2013/04/o-jovem-e-o-adolescente-na-cena-social.pdf 
Rosa, M. D. (2012). Psicanálise implicada: vicissitudes das práticas clinicopolíticas. Revista da Associação Psicanalítica de Porto Alegre Psicanálise: invenção e intervenção, (41/42), 29-38.

Rosa, M. D., \& Vicentin, M. C. (2010). Os intratáveis: o exílio do adolescente do laço social pelas noçôes de periculosidade e irrecuperalidade. Psicologia Politica, 19(10), 107-124. Recuperado de http://pepsic.bvsalud.org/pdf/rpp/v10n19/v10n19a10.pdf

Soares, L. E. (2004). Juventude e violência no Brasil contemporâneo. In R. R. Novaes, \& P. Vannuchi (Orgs.), Juventude e sociedade: trabalho, educação, cultura e participação (pp. 304). São Paulo, SP: Editora Fundação Perseu Abramo.

Telles, V. S. \& Hirata, D. V. (2007). Cidade e práticas urbanas: nas fronteiras incertas entre o ilegal, o informal e o ilícito. Estudos Avançados, 21(61), 173-191. Recuperado de http://dx.doi. org/10.1590/S0103-40142007000300012

Torossian, S. D. (2011). "Sem limites" ou "sem saída"? Ensaio preliminar. In Comissão de Aperiódicos da Associação Psicanalítica de Porto Alegre (Org.), Autoridade e violência (pp. 206-215). Porto Alegre, RS: APPOA.

Waiselfisz, J. J. (2015). Mapa da violência: adolescentes de 16 e 17 anos no Brasil. Rio de Janeiro, RJ: Flasco. Recuperado de www.mapadaviolencia.org.br/pdf2015/mapaviolencia2015_adolescentes.pdf

Wedekind, F. (1891). O despertar da primavera. Recuperado de http://www.teatrosemcortinas. ia.unesp.br/Home/HistoriadoTeatroMundial33/o-despertar-da-primavera.pdf

\section{NOTAS}

1. Pesquisa realizada no Instituto de Psicologia no Programa de Pós-Graduação Psicanálise: Clínica e Cultura da Universidade Federal do Rio Grande do Sul (UFRGS) com o título "A passagem adolescente em contextos de vulnerabilidade e exclusão social” (2017).

2. O sociólogo Waiselfisz (2015), autor do Mapa da violência, aponta o crescimento preocupante do número de jovens mortos por homicídios. De 1980 a 2013 os homicídios passaram de $0,7 \%$ para $13,9 \%$ na faixa de zero a 19 anos. O autor destaca que, dentre todas as causas externas de morte de jovens, a violência é a principal.

3. O Centro de Referência Especializado de Assistência Social (CREAS) trabalha no acolhimento e no acompanhamento das famílias e dos indivíduos em situaçóes de violação de direitos, buscando a superação destas violaçóes.

4. O Centro de Referência de Assistência Social (CRAS) oferta serviços de proteção social básica prevenindo situações de vulnerabilidade e risco social e buscando a promoção da cidadania das famílias e indivíduos atendidos.

342 Estilos clin., São Paulo, v. 23, n. 2, maio/ago. 2018, 322-343. 
5. Os nomes utilizados são fictícios para preservar a identidade dos jovens e famílias. Foi utilizado o Termo de Consentimento Livre e Esclarecido com o adolescente e sua família, concordando em participar da pesquisa e aceitando o uso para publicações e estudos científicos.

6. Serviço de Convivência e Fortalecimento de Vínculos (SCFV). Serviço oferecido a crianças e adolescentes em situação de vulnerabilidade social e violaçóes de direitos no contraturno escolar, que desenvolve atividades recreativas e esportivas conforme preconizado pelo Sistema Único de Assistência Social (SUAS).

7. Ver em: <www.pronatec2015.com>. Acesso em: 9 ago. 2016.

8. Ver em: <www.aprendizagemlegal.org.br>. Acesso em: 9 ago. 2016. E Lei da Aprendizagem no 10097/2000, disponível em: <www.planalto.gov.br/ccivil_03/leis/10097.htm>. Acesso em: 9 ago. 2016.

marisabw@gmail.com

Rua Vitor Meireles, 200/804 90430-160 - Porto Alegre - RS - Brasil

luciane.conti@ufrgs.br Rua Ramiro Barcelos, 2600/130 90035-003 - Porto Alegre - RS - Brasil 